\title{
Evolutionary Game Analysis of E-Commerce Intellectual Property Social Cogovernance with Collective Organizations
}

\author{
Ji Li $\oplus^{1}$ and Chunming Xu $\mathbb{1}^{2}$ \\ ${ }^{1}$ School of Management, Shanghai University, Shanghai 200444, China \\ ${ }^{2}$ Shanghai International College of Intellectual Property, Tongji University, Shanghai 200092, China \\ Correspondence should be addressed to Ji Li; ipliji@shu.edu.cn
}

Received 20 September 2021; Accepted 26 January 2022; Published 14 February 2022

Academic Editor: Zhen Zhang

Copyright ( $) 2022 \mathrm{Ji} \mathrm{Li}$ and Chunming Xu. This is an open access article distributed under the Creative Commons Attribution License, which permits unrestricted use, distribution, and reproduction in any medium, provided the original work is properly cited.

\begin{abstract}
China's E-commerce market is very active. Despite the impact of COVID-19, the market has ushered in major development opportunities. Alongside, the level of intellectual property protection in China is constantly improving. However, there are relatively few studies on intellectual property protection in the field of E-commerce. This study introduces the theory of social cogovernance and explores the construction of China's E-commerce intellectual property protection system with the participation of collective organizations. Evolutionary game method is applied to model construction. Through numerical simulation, the study analyzes the evolution of E-commerce platform and collective organization strategic choice. The results depict that improving the open space provided by E-commerce platforms for collective organizations and strengthening their public service capabilities can promote the construction of social cogovernance systems. The establishment of reasonable reward and punishment mechanisms can increase cooperation enthusiasm. We also discuss the theoretical and practical implications for governments, E-commerce platforms, and collective organizations, to improve the level of intellectual property protection in E-commerce. This study can provide suggestions for China's E-commerce intellectual property protection, improve the overall level of intellectual property protection in China, and provide a reference for global E-commerce intellectual property protection.
\end{abstract}

\section{Introduction}

Scientific and technological progress and innovation promote the development of economies and societies. They are key factors for promoting sustainable competitive advantages of organizations and nations [1-5]. Intellectual property rights, as an important manifestation of science and technology, have been receiving increasing attention. The intellectual property protections are necessary because of continuous advancements in China's intellectual property work. The Chinese government has gained knowledge from developed countries and has been gradually promoting the protection of intellectual property rights. Concurrently, according to "E-Commerce in China" (2019), issued by the Department of E-commerce and Information Technology of China's Ministry of Commerce, China's E-commerce transaction volume was 34.81 trillion yuan in 2019, indicating an annual increase of $6.7 \%$. In addition, the China Internet Network Information Centre noted that, in December 2020, the Internet penetration rate in China had reached $70.4 \%$, with 989 million Internet users. In particular, the impact of COVID-19 has opened up opportunities for the E-commerce market to usher in major developments.

However, the problem of making and selling counterfeit products and infringing on intellectual property rights in the field of E-commerce has gradually become prominent and caused many disputes [6]. This has become a major issue that restricts the sustainable and healthy development of China's E-commerce. Further research is required to protect intellectual property rights in this field. E-commerce activities involve a large variety of entities and resources, and failure in coordination may result in significant economic losses [7]. However, intellectual property rights are highly technical, and the government and E-commerce platforms have 
imperfect policies and methods for intellectual property protections in the E-commerce market. Although the new E-commerce Law was implemented in 2019 to regulate related issues, the related legal system is yet to improve, as new problems continue to emerge in the field. Therefore, we need innovative ways to protect intellectual property rights. While the Chinese government has formulated many guidelines, the "Opinions on Strengthening Intellectual Property Protection" [8], issued in 2019, indicates that China should improve its intellectual property protection mechanisms and strengthen its social supervision and cogovernance. In this perspective, the introduction of social cogovernance theory in the field of E-commerce is innovative.

Collective organizations represent the consistent ways in which individual members think, act, and feel $[9,10]$ and can promote the sustainable development of the group [11]. At the same time, collective organizations must preserve the private interests of the member firms and provide social welfare services to them $[12,13]$. In addition, individual members perceive a threat to the collective organization as a personal threat, even if the threat is directed towards another group member [14]. Collective organizations, such as consumer protection associations and industry associations, play an important role in protecting the rights and interests of consumers and rights holders in E-commerce activities. However, the fundamental purpose of collective organizations participating in the game is to maximize their own interests, and their strategic choices must be judged based on the ultimate benefits they receive [15]. In addition, there are many problems that collective organizations face when participating in the protection of intellectual property rights.

A review of existing literature reveals a lack of effective research on intellectual property protections in the field of E-commerce based on the theory of social cogovernance. This study explores the mechanism construction and factors influencing the participation of collective organizations in the social governance of E-commerce intellectual property protection. The study formulates an evolutionary game model between E-commerce platforms and collective organizations under the government's supervision, discusses evolutionary stability strategies (ESS) under different modes, and provides suggestions for improvement in China's E-commerce intellectual property protection levels. We contribute by exploring the construction method of E-commerce intellectual property protection systems based on the evolutionary game method and social cogovernance theory and by illustrating it with a numerical simulation.

Our study is closely related to two research streams: (1) the application and practice of social cogovernance theory and (2) the application of evolutionary game theory in intellectual property protection.

The governance activities are the management mechanisms of coordination and cooperation between the government and social entities [16]. China's governance system reform is imminent with the continuous transformation of society. The concept of "a monitoring mechanism with full public participation" first appeared in the Chinese government's official documents, "Report of the Work of Government," in 2014. Social cogovernance is a model of social autonomy under government's supervision [17-19]. The concept of applying social cogovernance in the protection of intellectual property is in line with China's social realities and policy needs. Presently, the concept of social cogovernance in the field of intellectual property protection theory has not been studied in depth till date. However, there is much research in the field of food safety. Yang et al. [20] constructed an evolutionary game model between suppliers and producers to analyze food quality problems in China. Zhu et al. [21] considered the issue of food risk communication between food regulators and consumers in China. Wu et al. [22] proposed the connotation and operational logic of food safety cogovernance. This is systematically constituted by the roles, functions, and boundaries of public agencies, enterprises, and social forces. Wang [23] emphasized that, to modernize food safety governance, we must make the basic restructuring of its internal logic at the national level to reflect the features of contemporary Chinese society that shape food safety. Shen and Wei [24] noted that under the cogovernance model, the degree of online food safety is related to rigorous government's supervision and its punishment of enterprises and platforms. In addition, many scholars have studied the social cogovernance of food safety from the perspective of consumers $[25,26]$, industry organizations [25], third-party supervision agencies [27], the media [28], and psychological capital [29]. A handful of researchers have also investigated the theory of social cogovernance in other fields. For example, Yang and Li [30] and Li et al. [31] studied the social cogovernance system in ecological environmental protection and air pollution control.

E-commerce activities are complex and require coordination among multiple parties, as well as the cooperation of stakeholders [32, 33]. Therefore, it is critical to introduce the theory of social cogovernance in the protection of E-commerce intellectual property rights.

E-commerce activities have strong flexibility, relatively low costs, and high degrees of globalization. However, the degree of information asymmetry is deep, which leads to its rapid development and also causes the lemon effect [34-36]. Therefore, we need to reduce information asymmetry in E-commerce activities. In recent years, scholars have gradually introduced evolutionary game methods in the field of E-commerce to solve related problems. Shen et al. [37] analyzed the government's supervision on immoral behavior of explosive enterprises in E-commerce companies through the evolutionary game method and emphasized the importance of the government imposing penalties and consumers' support. Wen et al. [38] discussed the evolutionary game problem of government's supervision in online shopping quality control under various risk attitude combinations.

On analyzing existing literature, we found that the evolutionary game model has not been introduced to China's E-commerce intellectual property protection. However, the application of the game models in food safety 
governance, intellectual property financing, and other fields is worth noting. For example, Song et al. [39] discussed the interesting relationships and behaviors of public agencies, enterprises, and the citizens in food safety governance. They constructed a behavioral game analysis among the three. In light of the evolutionary game theory, Yang et al. [40] analyzed the intellectual property cooperation behaviors among governments, industries, and universities, and their significant predictors based on market and administrative supervision mechanisms. $\mathrm{Li}$ and $\mathrm{Xu}$ [41] studied the evolutionary game analysis of a financing model for intellectual property from a supply chain financial perspective. Therefore, it is feasible to introduce the evolutionary game analysis method into the field of China's E-commerce intellectual property protection.

In summary, there are few studies related to E-commerce intellectual property protection. Consequently, it is innovative to introduce the theory of social cogovernance in the protection of E-commerce intellectual property rights. Furthermore, the evolutionary game method provides a new perspective for the protection of E-commerce intellectual property rights. This study can provide suggestions for China's E-commerce intellectual property protection and is conducive to improving the level of intellectual property protection in China. Simultaneously, it can also provide a reference for global E-commerce intellectual property protection.

\section{Materials and Methods}

2.1. Problem Description. Introducing the theory of social cogovernance to study the evolution of stakeholder strategies in the field of E-commerce intellectual property can help improve the level of intellectual property protection in China. This study constructs a game relationship between E-commerce platforms and collective organizations under government's supervision and incentives and investigates the problem of social cogovernance in that system. From a social cogovernance perspective, the manner in which E-commerce platforms and collective organizations effectively cooperate can be considered the result of the mutual game. It is difficult for the game players to ensure that their strategic choices are the best choices when faced with incomplete information and limited rationality. Therefore, under different influencing factors, a gradual process takes place in the evolutionary game between the E-commerce platforms and collective organizations.

E-commerce platforms are the online platforms that provide services for transactions in the E-commerce market. They have certain responsibilities pertaining to the management and control of intellectual property infringement issues that may exist in E-commerce activities. The operation of E-commerce platforms incurs costs, and government's supervisory agencies reward or penalize the effectiveness of a platform's management and control. Collective organizations represent the overall interests of their members and can support their legitimate rights and interests. However, these organizations also need to cover their operating costs, and their public service capabilities determine whether they can adequately protect their members. E-commerce platforms can increase the supervisory benefits through cooperation with collective organizations only when the latter's public service capabilities are strong enough, and the cooperation between the two is carried out smoothly. Such cooperation also helps the collective organizations to effectively play the role of group representatives. An E-commerce platform creates a cooperation space for the collective organization. The organization then provides benefits to the E-commerce platform by providing public services in the cooperation space. Therefore, improving the ability and active nature of E-commerce platforms and collective organizations to comanage intellectual property infringement issues is an area worth exploring.

In addition, government's supervisory agencies that control the administrative supervision of intellectual property infringement in China would supervise E-commerce platforms and collective organizations and provide certain incentives to the two players who participate in social cogovernance cooperation. Conversely, the government would also penalize the inadequate protection of intellectual property rights that still occur under the conditions of cooperation.

The relationship among the game players in the E-commerce intellectual property social cogovernance system with collective organizations is shown in Figure 1.

\subsection{Research Hypotheses}

Hypothesis 1. Bounded Rationality. The players face bounded rationality. After the game starts, their strategic choices are random, and they may not find the Nash equilibrium [42]. The arbitrariness of the game's strategic choices leads to the gradual nature of the evolutionary game.

Hypothesis 2. Replication Dynamics. In the process of the evolutionary game, the players' strategic decision-making speed is slow. Consequently, we can describe the evolutionary and stable process of the game using the replication dynamic equation.

Hypothesis 3. Strategy. Different participants make different decisions when faced with different decision-making environments. The strategic choices of E-commerce platforms and collective organizations will affect each other in the social governance of intellectual property in an E-commerce system. The specific strategy hypotheses are as follows:

(1) The government is satisfied that E-commerce platforms accept the collective organizations' participation in the social cogovernance system. Therefore, when the two cooperate, the government tends to provide incentives to E-commerce platforms. When the protection of intellectual property rights is inadequate during the cooperation, the government tends to impose penalties on the E-commerce platforms.

(2) There are two options for E-commerce platforms: cooperation and noncooperation. $(x, 1-x)$ are the 


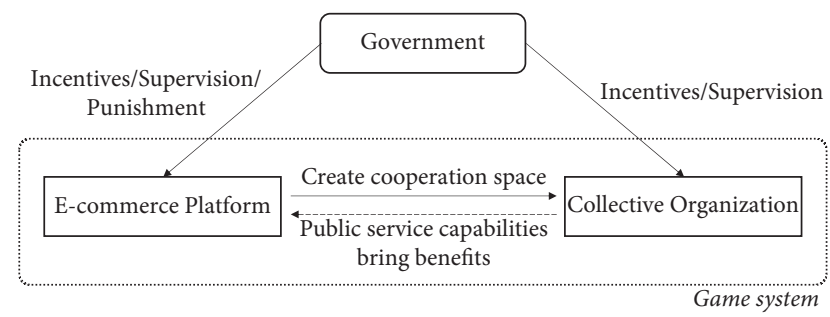

Figure 1: The system diagram of the E-commerce intellectual property social cogovernance with the collective organization.

probabilities of cooperation and noncooperation, respectively $(0 \leq x \leq 1)$. When $x=0$, it implies that the E-commerce platform is in a slower emerging cooperation space to a collective organization and refuses to conduct the social cogovernance activities. The original supervision cost and income of the E-commerce platform are $C_{p o}$ and $S_{p}\left(C_{p o}>0\right.$, $S_{p}>0$ ), respectively. When the E-commerce platforms cooperate with collective organizations, the cooperation coefficient of the E-commerce platform for the collective organization is $\mu(0 \leq \mu<1)$. The larger the value of $\mu$, the larger the cooperation space. At this time, the reward provided by the government for the active cooperation of E-commerce platforms is $M$. The simultaneous effect of these two factors can increase the revenue of the E-commerce platform. When protection of intellectual property rights is inadequate with cooperation, the penalty imposed by the government on E-commerce platforms is $P$.

(3) There are two options for collective organizations: cooperation and noncooperation, and the probabilities of the two choices are $(y, 1-y)$ and $(0 \leq y \leq 1)$. The operating cost of the collective organizations is $C_{c o}$. When a collective organization cooperates with an E-commerce platform, the cost of the cooperation between the two is $C_{p c}$. The public service capabilities of the collective organizations act on the E-commerce platform through the efficiency improvement coefficient $\rho(0 \leq \rho \leq 1)$. The incentive coefficient of the government for the collective organization to participate in the cooperation is $\varphi$ $(0 \leq \varphi \leq 1)$. Under the cooperative coefficient of E-commerce platform, the efficiency improvement coefficient, and the government's incentive coefficient, the collective organization influences the cooperation benefits of both parties through its public service capabilities $S_{p s}$. In other words, when a collective organization actively participates in cogovernance in a certain cooperative space, the stronger the public service capability and the higher the government's incentives, the higher the revenue the collective organization can obtain. The public service capabilities of collective organizations can also benefit E-commerce platforms in cooperation, such as reducing governance and docking costs. In a certain cooperation space, we express this benefit as the governance efficiency improvement of E-commerce platforms by collective organizations through public service capabilities. Higher improvement efficiency and stronger public service capability mean a higher degree of connection and better revenue for the E-commerce platform.

The relevant parameters used in this study are shown in Table 1. The payment income matrix is listed in Table 2.

2.3. Model Building. As shown in the matrix in Table 2, the expected revenue for cooperative and noncooperative E-commerce platforms are $U_{p 1}$ and $U_{p 2}$, respectively. The average expected return $U_{p 0}$ of the E-commerce platform's strategies is as follows:
The dynamic differential equation of the E-commerce platform is as follows:

$$
F(x)=\frac{\mathrm{d} x}{\mathrm{~d} t}=x(1-x)\left[y \cdot \mu\left(\rho S_{p s}+M-P\right)-C_{p c}\right] .
$$

Similarly, the expected revenue for cooperative and noncooperative collective organizations are $U_{c 1}$ and $U_{c 2}$, respectively. The average expected return $U_{c 0}$ is as follows:

$$
\begin{aligned}
& U_{p 2}=y\left(-C_{p o}+S_{p}\right)+(1-y)\left(-C_{p o}+S_{p}\right), \\
& U_{p 1}=y\left(-C_{p o}-C_{p c}+S_{p}+\mu \rho S_{p s}+\mu M-\mu P\right)+(1-y)\left(-C_{p o}-C_{p c}+S_{p}\right) .
\end{aligned}
$$

$$
\begin{aligned}
U_{c 0}= & y U_{c 1}+(1-y) U_{c 2}, \\
U_{c 2}= & x\left(-C_{c o}+S_{c}\right)+(1-x)\left(-C_{c o}+S_{c}\right), \\
U_{c 1}= & x\left(-C_{c o}-C_{p c}+S_{c}+\mu \varphi S_{p c}\right) \\
& +(1-x)\left(-C_{c o}-C_{p c}+S_{c}\right) .
\end{aligned}
$$

The dynamic differential equation of the collective organization is as follows: 
TABLE 1: The relevant variables.

\begin{tabular}{|c|c|}
\hline Variables & Definitions \\
\hline$C_{p o}$ & Original supervision cost of E-commerce platforms \\
\hline$C_{c o}^{p o}$ & Collective organizations' operating costs \\
\hline$C_{p c}$ & The cost of the cooperation between E-commerce platforms and collective organizations \\
\hline$S_{p}$ & Original income of E-commerce platforms \\
\hline$S_{c}^{P}$ & Original income of collective organizations \\
\hline$S_{p s}$ & The public service capabilities of collective organizations \\
\hline$\mu$ & Cooperative coefficient provided by E-commerce platforms for a collective organization \\
\hline$\rho$ & $\begin{array}{c}\text { The efficiency improvement coefficient provided by the collective organizations' public service capabilities for E-commerce } \\
\text { platforms }\end{array}$ \\
\hline$\varphi$ & Incentive coefficient of the government for collective organizations to participate in cooperation \\
\hline M & Government rewards for cooperation to E-commerce platforms \\
\hline$P$ & $\begin{array}{c}\text { Penalties by the government on the inadequate protection of intellectual property rights when E-commerce platforms conduct } \\
\text { cooperation activities }\end{array}$ \\
\hline
\end{tabular}

TABLE 2: The payment income matrix of E-commerce intellectual property social cogovernance with the collective organization.

\begin{tabular}{lcc}
\hline E-commerce platform & Cooperation & Collective organization \\
& & Noncooperation \\
\hline Cooperation & $-C_{p o}-C_{p c}+S_{p}+\mu \rho S_{p s}+\mu M-\mu P,,-C_{c o}-C_{p c}+S_{c}+\mu \varphi S_{p s}$ & $-C_{p o}-C_{p c}+S_{p},-C_{c o}+S_{c}$ \\
Noncooperation & $-C_{p o}+S_{p},-C_{c o}-C_{p c}+S_{c}$ & $-C_{p o}+S_{p},-C_{c o}+S_{c}$ \\
\hline
\end{tabular}

$$
\begin{aligned}
& \text { if } F(y)=0 \text {, then } y=0 \text { or } y=1, x^{*}=\frac{C_{p c}}{\mu \varphi S_{p s}}, \\
& \text { if } F(x)=0 \text {, then } x=0 \text { or } x=1, y^{*}=\frac{C_{p c}}{\mu\left(\rho S_{p s}+M-P\right)}, \\
& \qquad F(y)=\frac{\mathrm{d} y}{\mathrm{~d} t}=y(1-y)\left[x \cdot \mu \varphi S_{p s}-C_{p c}\right] .
\end{aligned}
$$

Five local equilibrium points were found as follows: $E_{1}(0,0), \quad E_{2}(0,1), E_{3}(1,0), E_{4}(1,1)$, and $E_{5}\left(x^{*}, y^{*}\right)$. Thereafter, the evolutionary stability was analyzed.

\section{Results and Discussion}

3.1. The Jacobian Matrix Stability Analysis. As suggested by Friedman [43], the stability of the equilibrium points can be evaluated from the Jacobian matrix. Using the Jacobian matrix, the replication dynamics equation is as follows:

$$
\begin{aligned}
& {\left[\begin{array}{rr}
1-2 x\left[y \cdot \mu\left(\rho S_{p s}+M-P\right)-C_{p c}\right] & x(1-x)\left[\mu\left(\rho S_{p s}+M-P\right)\right] \\
y(1-y) \mu \varphi S_{p s} & (1-2 y)\left[x \cdot \mu \varphi S_{p s}-C_{p c}\right]
\end{array}\right]} \\
& J=\left[\begin{array}{ll}
J_{1} & J_{2} \\
J_{3} & J_{4}
\end{array}\right]=\left[\begin{array}{ll}
\frac{\partial F(x)}{\partial x} \frac{\partial F(x)}{\partial y} \\
\frac{\partial F(y)}{\partial x} \frac{\partial F(y)}{\partial y}
\end{array}\right]=.
\end{aligned}
$$

The Jacobian determinant is

$$
\begin{gathered}
x(1-x)\left[\mu\left(\rho S_{p s}+M-P\right)\right] y(1-y) \mu \varphi S_{p s}, \\
\operatorname{det} J=1-2 x\left[y \cdot \mu\left(\rho S_{p s}+M-P\right)-C_{p c}\right](1-2 y)\left[x \cdot \mu \varphi S_{p s}-C_{p c}\right]-.
\end{gathered}
$$

The Jacobian trace is 


$$
\operatorname{tr} J=1-2 x\left[y \cdot \mu\left(\rho S_{p s}+M-P\right)-C_{p c}\right]+(1-2 y)\left[x \cdot \mu \varphi S_{p s}-C_{p c}\right]
$$

The Jacobian determinant values and traces are shown in Table 3 .

The discussion and analyses of ESS in different situations are as follows.

Model I. When $S_{p s}<P-M / \rho$, there is always $\mu\left(\rho S_{p s}+M\right.$ $-P)-C_{p c}<0$. At this time, $(0,0)$ is the only ESS point. The public service capabilities of the collective organizations are too inadequate to participate in the social cogovernance activities of E-commerce intellectual property protection. The benefits of the E-commerce platforms participating in cooperation activities are always less than those of noncooperation. Therefore, they will not adopt cooperation strategies.

Model II. When $S_{p s}>P-M / \rho$, if $\mu>\max \left(C_{p c} / \rho S_{p s}+M-P, C_{p c} / \varphi S_{p s}\right),(0,0)$ and $(1,1)$ are ESS points. These function to address the situation between the E-commerce platforms and the collective organizations. This occurs when both choose cooperation, or both choose noncooperation. The evolutionary stability of the local equilibrium points in Model II is analyzed, as shown in Table 4.

As presented in Figure 2, the area OABC represents the system's mixed strategy space and the dynamic evolution process of Model II. When the initial state of the system falls in different areas, there will be different stable results for strategy selections. When the initial state falls in area CAXB, the ESS point is $(1,1)$. When the initial state falls in the area $\mathrm{OAXB}$, the ESS point is $(0,0)$.

Inference 1 . When $S_{p s}>P-M / \rho$, $\mu>\max \left(C_{p c} / \rho S_{p s}+M-P, C_{p c} / \varphi S_{p s}\right)$; the higher the coefficient of the openness of the E-commerce platform to the collective organization, the greater the possibility of social cogovernance between the two.

With a change in the system parameters, the saddle point $X\left(x^{*}, y^{*}\right)$ will change, and the equilibrium point of the evolutionary games will change accordingly. As shown in Figure 2, when $\mu$ changes, the saddle point $X$ changes. The area of $\mathrm{OAXB}$ is

$$
S=\frac{1}{2}\left(x^{*}+y^{*}\right)=\frac{1}{2}\left(\frac{C_{p c}}{\mu \varphi S_{p s}}+\frac{C_{p c}}{\mu\left(\rho S_{p s}+M-P\right)}\right)
$$

Then,

$$
\frac{\partial S}{\partial \mu}=-\frac{C_{p c}}{2 \mu^{2} \varphi S_{p s}}-\frac{C_{p c}}{2 \mu^{2}\left(\rho S_{p s}+M-P\right)} .
$$

It is clear that $\partial S / \partial \mu<0$. Therefore, when $\mu$ increases, the area of $S$ decreases. The broken line AXB moves to point $\mathrm{O}$, and the probability of any point in the plane falling in the CAXB area increases.
Inference 2. When $S_{p s}>P-M / \rho$, $\mu>\max \left(C_{p c} / \rho S_{p s}+M-P, C_{p c} / \varphi S_{p s}\right)$; the stronger the public service capabilities of the collective organizations, the greater the possibility of social cogovernance between the two.

As shown in Figure 2 and Inference 1, we have

$$
\frac{\partial S}{\partial S_{p s}}=-\frac{C_{p c}}{2 \mu \varphi S_{p s}^{2}}-\frac{\rho C_{p c}}{2 \mu\left(\rho S_{p s}+M-P\right)^{2}} .
$$

When $S_{p s}$ increases, the area of $S$ decreases and the broken line $A X B$ moves to point $O$. The probability of any point in the plane falling in the CAXB area increases.

Inferences 1 and 2 show that when the cooperative coefficient provided by the E-commerce platform for the collective organization increases, or the public service capabilities of the collective organization increase, the possibility of cooperation between the two will also increase. In this way, both parties guarantee the basis for the construction of a social cogovernance system for the intellectual property protection. When the E-commerce platform limits the open space for cooperation, or the public service capacities of the collective organizations are insufficient, the two parties are more inclined to cooperate.

Model III. When $S_{p s}>P-M / \rho$, if $C_{p c} / \varphi S_{p s}<\mu<C_{p c} / \rho S_{p s}+M-P$, point $(0,0)$ is the ESS point. This stable strategy is not what the system pursues. Table 5 shows the evolutionary stability of the local equilibrium points in Model III. The phase diagram of Model III is presented in Figure 3.

Model IV. When $S_{p s}>P-M / \rho$, if $C_{p c} / \rho S_{p s}+M-P<\mu<C_{p c} / \varphi S_{p s}$, point $(0,0)$ is the ESS point. This stable strategy is not what the system pursues. Table 6 shows the evolutionary stability of the local equilibrium points in Model IV. The phase diagram of Model IV is presented in Figure 4.

Model V. When $S_{p s}>P-M / \rho$, if $0 \leq \mu<\min \left(C_{p c} / \rho S_{p s}+M-P, C_{p c} / \varphi S_{p s}\right)$, point $(0,0)$ is the ESS point. This stable strategy is not what the system pursues. Table 7 shows the evolutionary stability of the local equilibrium points in Model V. The phase diagram of Model $\mathrm{V}$ is presented in Figure 5.

3.2. System Simulation Analysis. This study used MATLAB software to simulate the dynamic evolution process of the social cogovernance system under different initial conditions or influencing factors. This helped us understand the strategic choices of the E-commerce platforms and the collective organizations better. According to the situation of E-commerce markets [44], the various variables in the game payoff function were set as follows:

Case 1. We set $C_{p c}=2, S_{p s}=3, \mu=0 \cdot 5, \rho=0 \cdot 9, \varphi=0 \cdot 5$, $M=2$, and $P=5$. The conditions of Model I were met. We 
TABle 3: The Jacobian determinant value and the trace.

\begin{tabular}{lcc}
\hline$(x, y)$ & $\operatorname{det} J$ & $t r J$ \\
\hline$E_{1}(0,0)$ & $C_{p c}^{2}$ & $-2 C_{p c}$ \\
$E_{2}(0,1)$ & $C_{p c}\left[\mu\left(\rho S_{p s}+M-P\right)-C_{p c}\right]$ & $\mu\left(\rho S_{p s}+M-P\right)$ \\
$E_{3}(1,0)$ & $C_{p c}\left(\mu \varphi S_{p s}-C_{p c}\right)$ & $\mu \varphi S_{p s}$ \\
$E_{4}(1,1)$ & {$\left[\mu\left(\rho S_{p s}+M-P\right)-C_{p c}\right]\left(\mu \varphi S_{p s}-C_{p c}\right)$} & $-\left[\mu\left(\rho S_{p s}+M-P\right)-C_{p c}\right]-\left(\mu \varphi S_{p s}-C_{p c}\right)$ \\
$E_{5}\left(x^{*}, y^{*}\right)$ & $\Delta \neq 0^{* *}$ & 0 \\
\hline
\end{tabular}

${ }^{* *}, \Delta=-x^{*} y^{*}\left(1-x^{*}\right)\left(1-y^{*}\right)\left[\mu\left(\rho S_{p s}+M-P\right)\right] \mu \varphi S_{p s}$.

TABLE 4: The stability analysis of Model II.

\begin{tabular}{lccc}
\hline$(x, y)$ & $\operatorname{det} J$ & $\operatorname{tr} J$ & Results \\
\hline$E_{1}(0,0)$ & + & - & ESS point \\
$E_{2}(0,1)$ & + & + & Unstable point \\
$E_{3}(1,0)$ & + & + & Unstable point \\
$E_{4}(1,1)$ & + & - & SS point \\
$E_{5}\left(x^{*}, y^{*}\right)$ & - & 0 & Saddle point \\
\hline
\end{tabular}

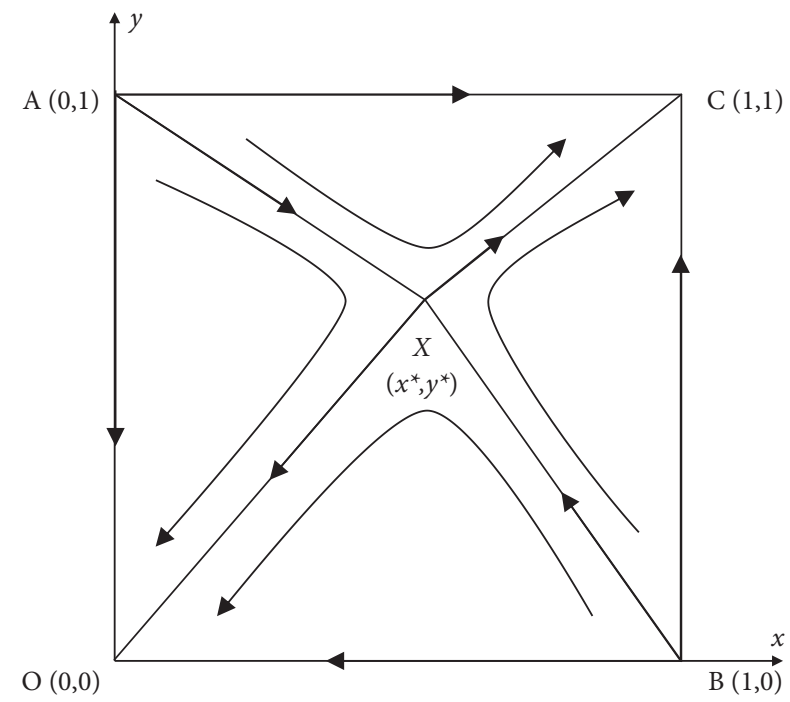

FIgUre 2: Phase diagram of Model II.

Table 5: The stability analysis of Model III.

\begin{tabular}{lccc}
\hline$(x, y)$ & $\operatorname{det} J$ & $\operatorname{tr} J$ & Results \\
\hline$E_{1}(0,0)$ & + & - & ESS point \\
$E_{2}(0,1)$ & - & Uncertain & Saddle point \\
$E_{3}(1,0)$ & + & + & Unstable point \\
$E_{4}(1,1)$ & - & Uncertain & Saddle point \\
$E_{5}\left(x^{*}, y^{*}\right)$ & - & 0 & Saddle point \\
\hline
\end{tabular}

analyzed the influence of the initial state value of $x(0)$ and $y(0)$ on the evolutionary game process and the results when $S_{p s}<P-M / \rho$.

The values were $(0 \cdot 1,0 \cdot 1),(0 \cdot 3,0 \cdot 3),(0 \cdot 5,0 \cdot 5)$, $(0 \cdot 7,0 \cdot 7)$, and $(0 \cdot 9,0 \cdot 9)$ for the initial state $(x, y)$. The ESS analysis is shown in Figure 6.

As shown in Figure 6, regardless of the initial state of the evolution, the final strategic choice of the system is noncooperation, because the public service capabilities that the collective organizations can provide are too weak. They

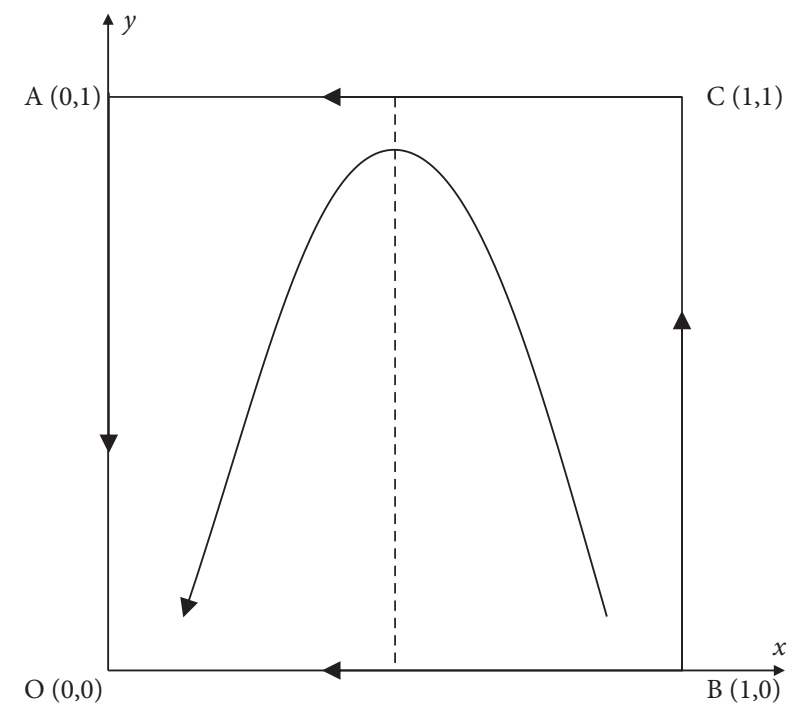

Figure 3: Phase diagram of Model III.

TABLE 6: The stability analysis of Model IV.

\begin{tabular}{lccc}
\hline$(x, y)$ & $\operatorname{det} J$ & $\operatorname{tr} J$ & Results \\
\hline$E_{1}(0,0)$ & + & - & ESS point \\
$E_{2}(0,1)$ & + & + & Unstable point \\
$E_{3}(1,0)$ & - & Uncertain & Saddle point \\
$E_{4}(1,1)$ & - & Uncertain & Saddle point \\
$E_{5}\left(x^{*}, y^{*}\right)$ & - & 0 & Saddle point \\
\hline
\end{tabular}

cannot assume the responsibility of participating in the E-commerce's intellectual property protection social cogovernance system. Therefore, neither the E-commerce platforms nor the collective organizations will choose to cooperate in social cogovernance.

Case 2. We set $C_{p c}=2, S_{p s}=15, \mu=0.5, \rho=0.9$, $\varphi=0 \cdot 5, M=2$, and $P=5$. The conditions of Model II were met. We analyzed the influence of the initial states $(x, y), \mu$, $S_{p s}, \rho, M$, and $P$ on the evolutionary game process and results:

(1) If the initial state $(x, y)$ is set to $(0 \cdot 1,0 \cdot 1)$, $(0 \cdot 3,0 \cdot 3), \quad(0 \cdot 5,0 \cdot 5), \quad(0 \cdot 7,0 \cdot 7), \quad$ and $(0 \cdot 9,0 \cdot 9)$, then the ESS is as presented in Figure 7.

As shown in Figure 7, the cooperative coefficient $(\mu=0 \cdot 5)$ and the evolutionary stable state of the 


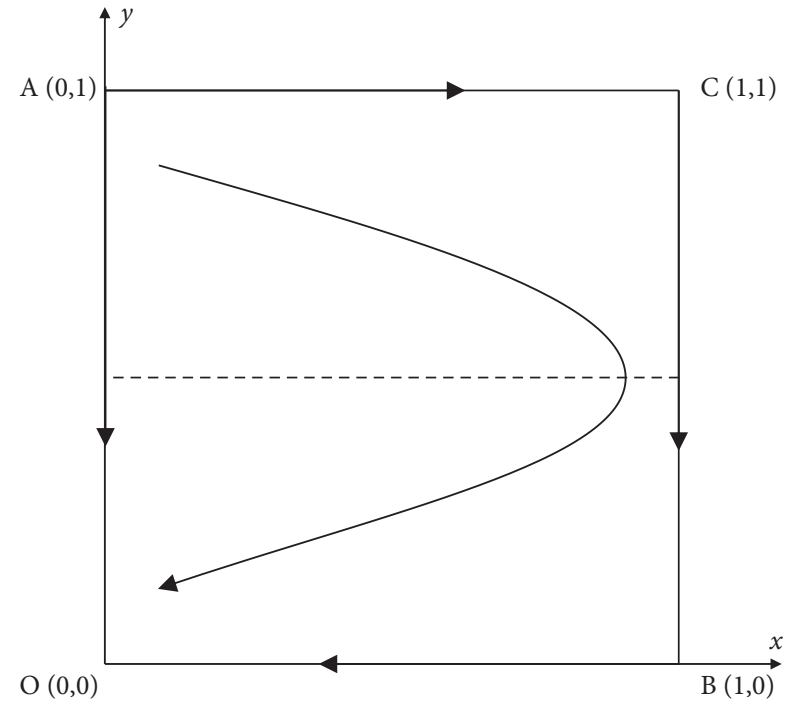

Figure 4: Phase diagram of Model IV.

TABLE 7: The stability analysis of Model V.

\begin{tabular}{lccc}
\hline$(x, y)$ & $\operatorname{det} J$ & $\operatorname{tr} J$ & Results \\
\hline$E_{1}(0,0)$ & + & - & ESS point \\
$E_{2}(0,1)$ & - & Uncertain & Saddle point \\
$E_{3}(1,0)$ & - & Uncertain & Saddle point \\
$E_{4}(1,1)$ & + & + & Unstable point \\
$E_{5}\left(x^{*}, y^{*}\right)$ & - & 0 & Saddle point \\
\hline
\end{tabular}

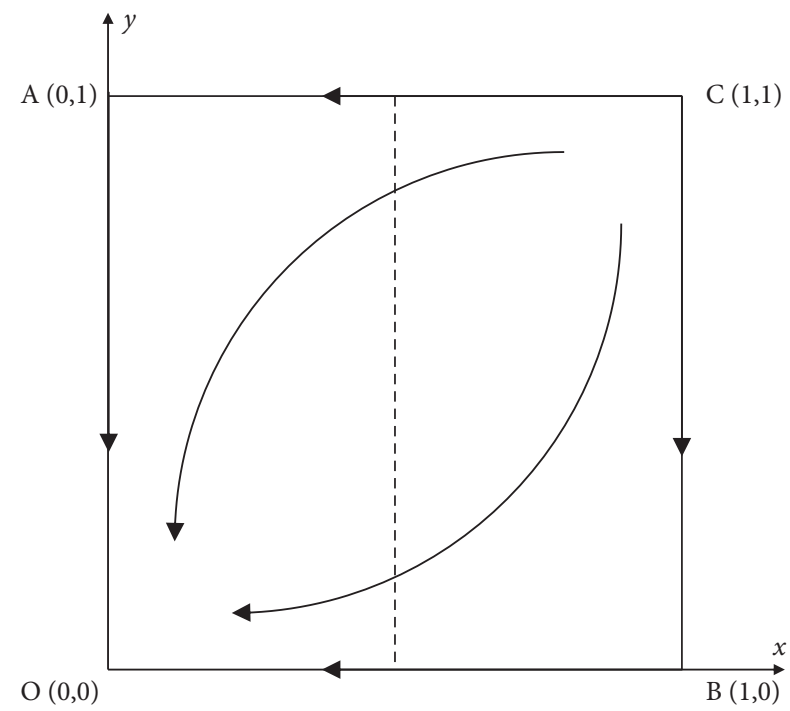

Figure 5: Phase diagram of Model V.

system depend on different initial values. As shown in Figure $8, X\left(x^{*}, y^{*}\right)=(0 \cdot 53,0 \cdot 38)$. When the initial state $(x, y)$ is in the CAXB area, the system will eventually stabilize at point $(1,1)$. As the result shows, the E-commerce platform and the collective organization choose cooperation. Consequently, when the two parties' initial willingness to cooperate

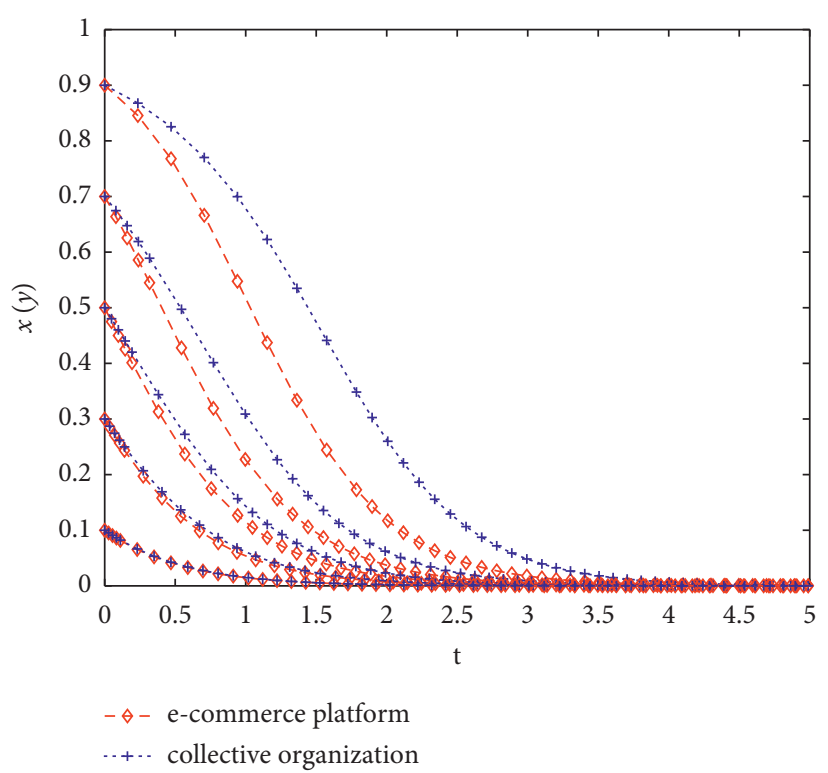

Figure 6: The stability analysis of Model I.

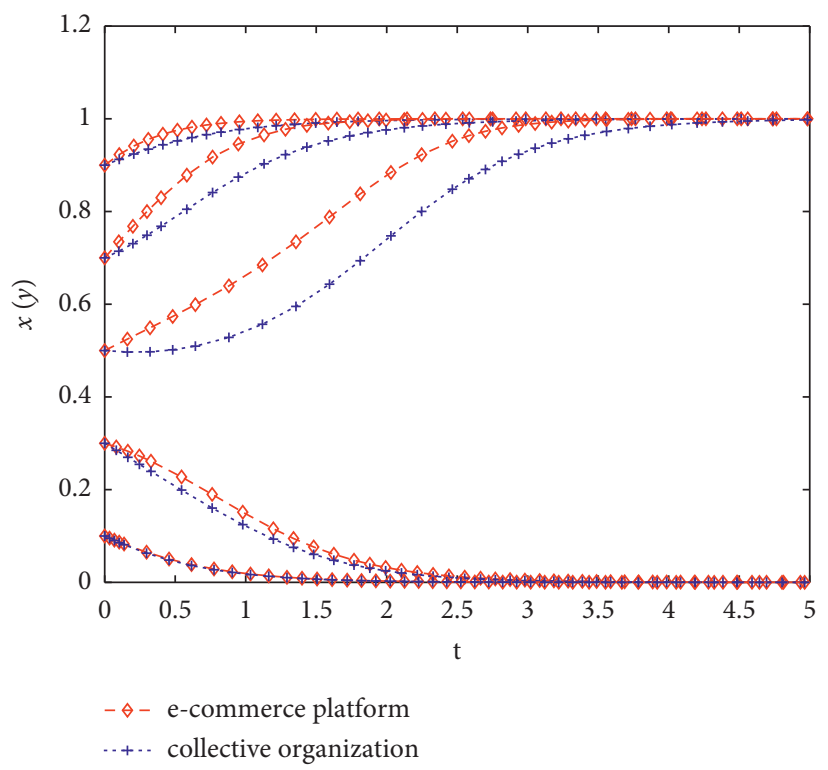

FIgUre 7: The stability analysis of Model II $(\mu=0 \cdot 5)$.

is high, the E-commerce platform and the collective organization can finally achieve cooperation. Therefore, under the premise that collective organizations have sufficient public service capabilities, we should encourage E-commerce platforms and collective organizations to participate in E-commerce intellectual property social cogovernance systems. They should also enhance the willingness of both parties to cooperate and, finally, to form cogovernance systems.

(2) If $\mu=0 \cdot 7, \mu=0 \cdot 5, \mu=0 \cdot 3$, and $\mu=0 \cdot 1$ are assigned to $\mu$, respectively, then the ESS is as presented in Figure 9. 


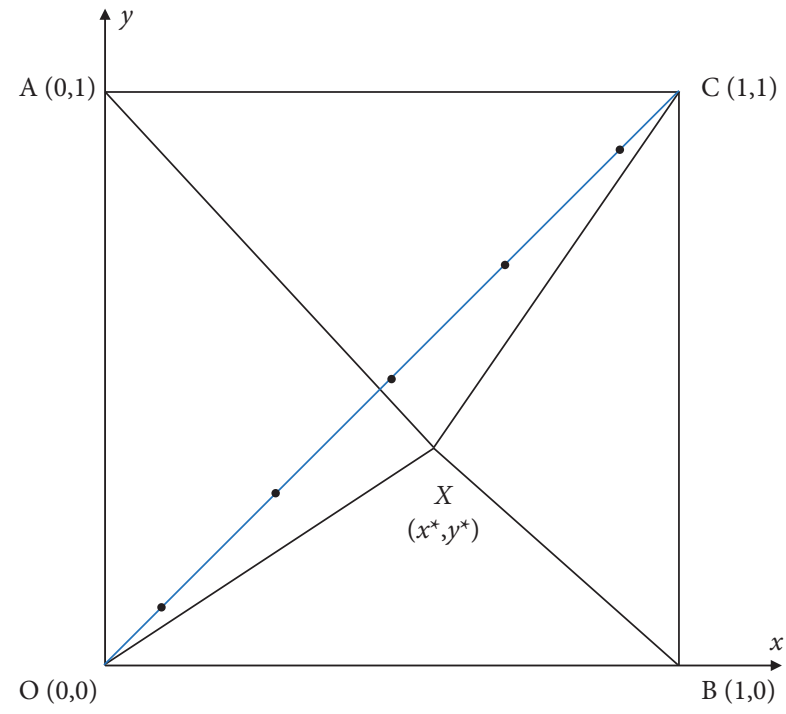

Figure 8: $X$ and initial value point.

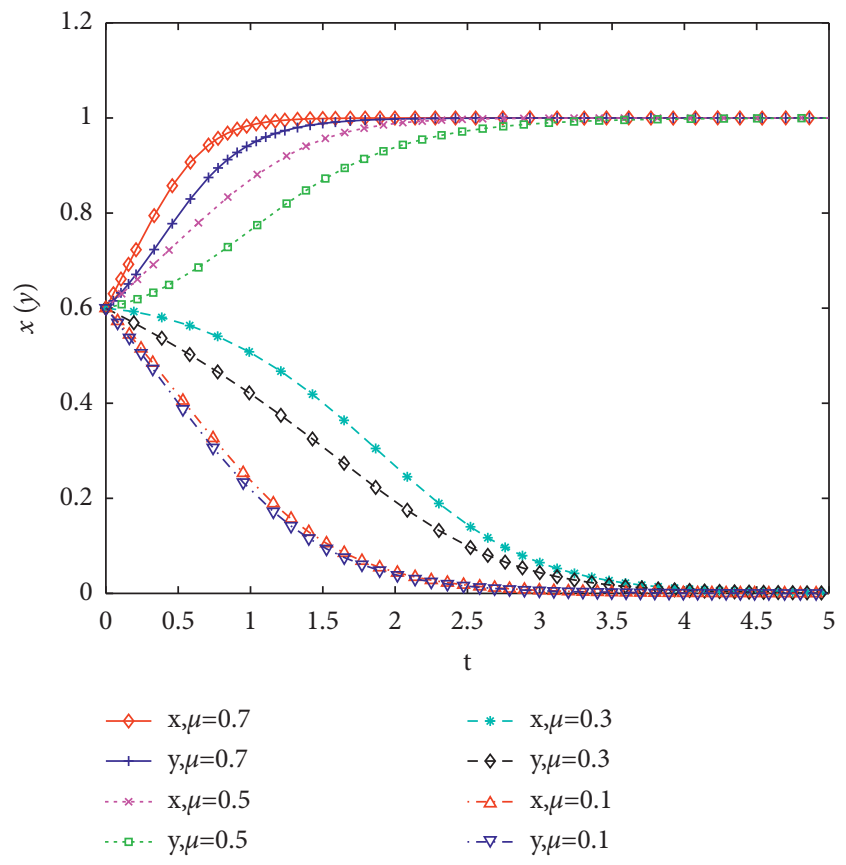

FIgURE 9: The stability analysis of Model II under different $\mu$.

As shown in Figure 9, in the process of a system's strategic evolution and stability, the degree of openness of an E-commerce platform promotes the evolution of the cooperation strategies of a collective organization. As the value of $\mu$ increases, the collective organizations increase their willingness to choose active cooperation in the construction of the social cogovernance system. The higher the degree of openness, the shorter the time to reach a stable state in the cooperation strategy, resulting in more enthusiasm for cooperation. Conversely, when the value of $\mu$ is reduced to a certain limit (such as $\mu=0 \cdot 3$ ), Models III and IV are satisfied, and the enthusiasm to cooperate decreases. In addition, when the value of $\mu$ continues to decrease (such as $\mu=0 \cdot 1$ ), Model $\mathrm{V}$ is satisfied. The benefits from choosing to cooperate are noticeably lower than the benefits of noncooperation, and the evolution rate of reaching the stability of the noncooperation strategy is faster than when the value of $\mu$ is large. Therefore, within reasonable limits, E-commerce platforms provide collective organizations with greater space for cooperation and have positive impacts on the collective organizations' willingness to cooperate.

Since the strategic stability point of Models III, IV, and $\mathrm{V}$ is $(0,0)$, it is not suitable for constructing a social cogovernance system. The results of the simulation are similar to those of Model I. The simulation is not discussed.

(3) If $S_{p s}=40, S_{p s}=15, S_{p s}=10$, and $S_{p s}=5$ are, respectively, assigned to $S_{p s}$, then the ESS is as presented in Figure 10

As shown in Figure 10, in the process of a system's strategic evolution and stability, strong public service capabilities of collective organizations promote the evolution of E-commerce platform cooperation strategies. As the value of $S_{p s}$ increases, the E-commerce platforms increase their willingness to choose active cooperation in the construction of the social cogovernance system. The stronger the public service capabilities, the shorter the time to reach a stable state in the cooperation strategy, the higher the cooperation enthusiasm, and conversely, the lower the cooperation enthusiasm. Improving the public service capabilities of collective organizations has positive effects on enhancing the willingness of E-commerce platforms to cooperate.

(4) If $\rho=0 \cdot 9, \rho=075, \rho=0 \cdot 6$, and $\rho=0.45$ are, respectively, assigned to $\rho$, then the ESS is as presented in Figure 11.

As shown in Figure 11, the efficiency improvement coefficient, provided by the collective organizations' public service capabilities for E-commerce platforms, has a positive effect on the system's stability. When the efficiency improvement coefficient is sufficiently high, the willingness to cooperate between E-commerce platforms and collective organizations is also high. When the efficiency improvement coefficient decreases (such as $\rho=0 \cdot 6$ ), the E-commerce platforms, being more sensitive to this influencing factor than the collective organizations, are more likely to choose a noncooperation strategy. When the efficiency improvement coefficient is lower than a certain value, E-commerce platforms and collective organizations are not able to obtain sufficient benefits from cooperation and choose the noncooperation strategy. Therefore, while improving the public service capabilities in collective organizations, it is also necessary to strengthen the efficiency improvement coefficient, provided by the public service capabilities of collective organizations to 


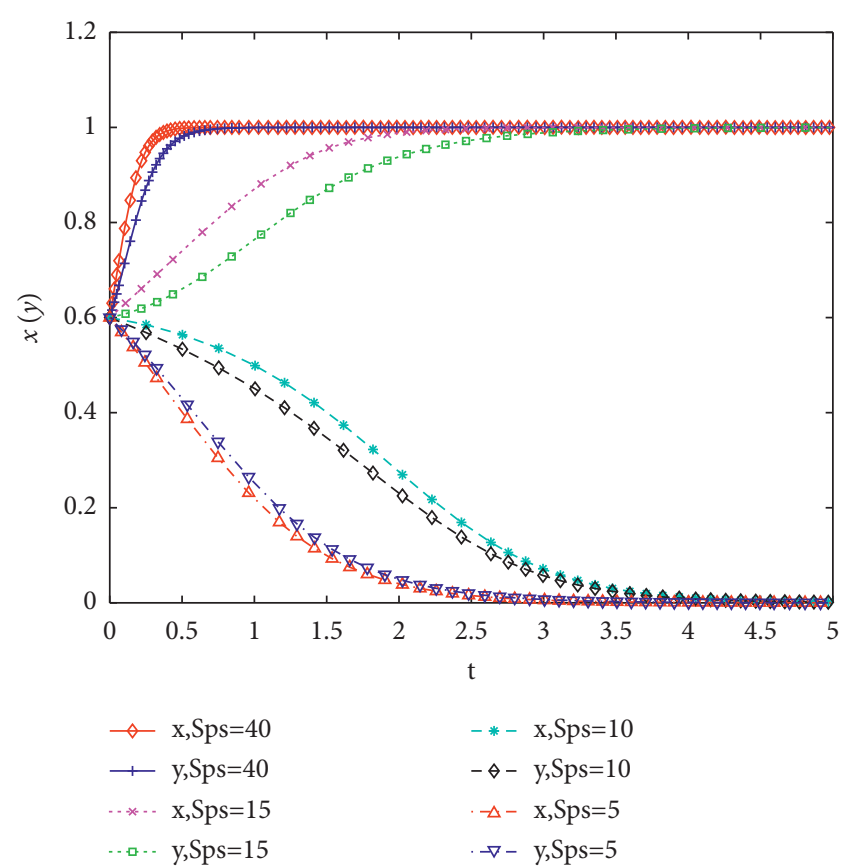

FIgURE 10: The stability analysis of Model II under different $S_{p s}$.

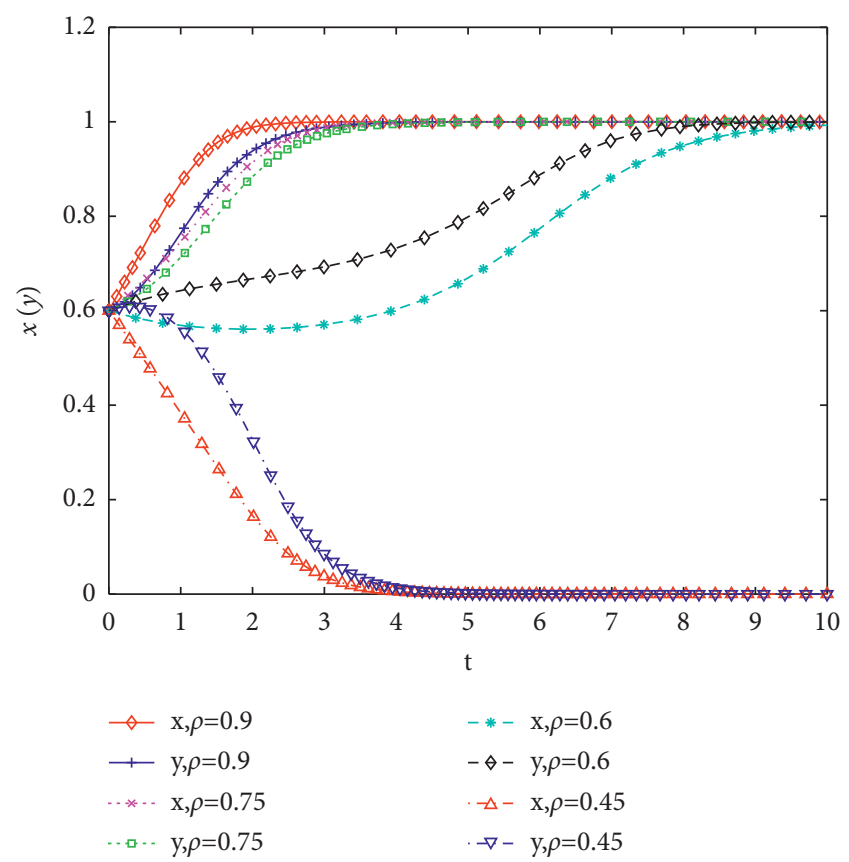

FIgURE 11: The stability analysis of Model II under different $\rho$.

E-commerce platforms. This can effectively improve the cooperation willingness of E-commerce platforms and collective organizations. This also applies to the construction and stability of the social cogovernance system for the protection of intellectual property on E-commerce platforms.

(5) If $M=10, P=5 ; M=2, P=5 ; M=5, P=10$; and $M=5, P=15$ are assigned to $M$ and $P$, respectively, then the ESS is as presented in Figure 12.

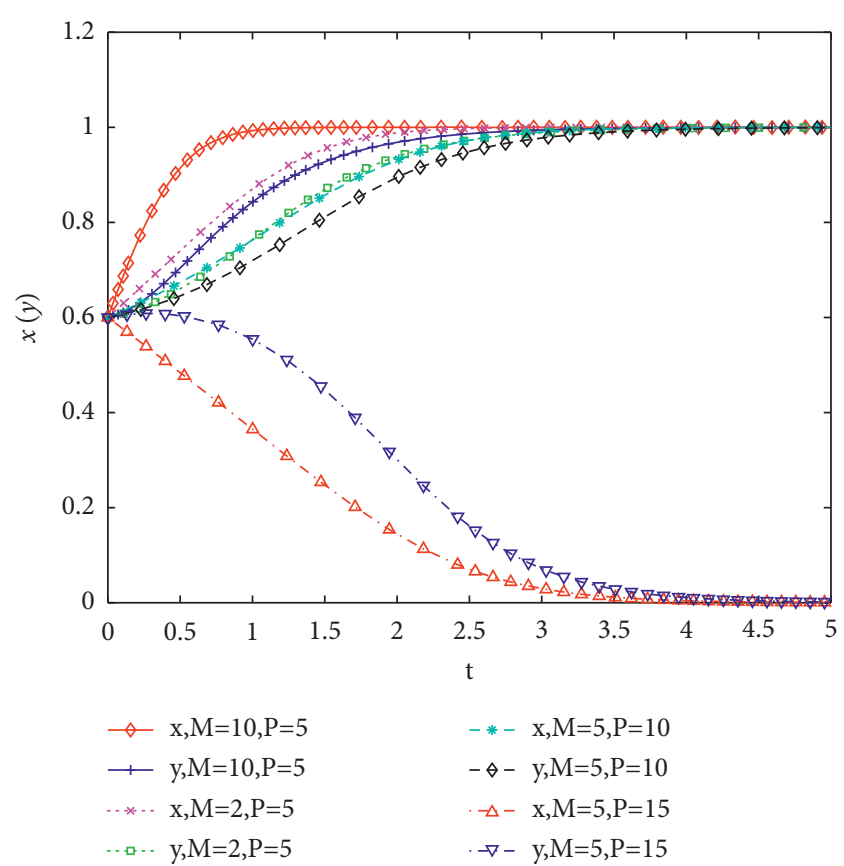

FIGURE 12: The stability analysis of Model II under different $M$ and $P$ values.

As shown in Figure 12, a proper reward and punishment mechanism can promote the active handling of infringement issues by E-commerce platforms and help avoid low-quality cooperation. When the penalty amount is fixed, a higher reward amount results in greater enthusiasm of the E-commerce platform. When the amount of the reward is fixed, the excessive penalty amount will make it difficult for E-commerce platforms to avoid punishment through cooperation benefits; that is, the system will tend not to cooperate to avoid possible losses. Therefore, setting a reasonable reward and punishment mechanism is crucial for improving the levels of intellectual property protection in E-commerce.

\section{Model Analysis and Conclusions}

4.1. Model Analysis. In the process of E-commerce platforms and collective organizations building E-commerce social cogovernance systems to protect intellectual property, two aspects affect the willingness of both parties to cooperate in social cogovernance: the size of the cooperative coefficient provided by the E-commerce platforms for the collective organizations and the strength of the public service capabilities of collective organizations. The greater the cooperative coefficient, the greater the role that the collective organization can play; in addition, the greater the possibility of it choosing to cooperate. When the public service capabilities of collective organizations are stronger, the benefits that the E-commerce platforms can obtain from public services are more; as a result, they cooperate more.

The government establishes a punishment and reward mechanism for the cooperation process. This can help avoid low-quality cooperation. However, an overly powerful 
punishment and reward mechanism may also inhibit the construction of E-commerce social cogovernance systems for intellectual property protections. When the benefits of cooperation are inadequate to cover the losses incurred from government punishments, the E-commerce platform and the collective organization will tend not to cooperate to avoid possible losses from the beginning. Therefore, providing a sufficient deterrence, increasing the range of rewards, and constructing reasonable government punishment and reward mechanisms can effectively increase the enthusiasm of E-commerce platforms and collective organizations to cooperate.

Consequently, when $\mu\left(\rho S_{p s}+M-P\right)-C_{p c}<0$, the open cooperation space of E-commerce platforms is too diminutive. In addition, the public service capabilities of the collective organizations are too weak to allow an E-commerce platform to obtain sufficient benefits from the cooperation. Therefore, regardless of the initial state, both parties will choose noncooperation. Simultaneously, if the intensity of the punishments and rewards from government departments is too high or the efficiency improvement coefficient provided by the collective organizations' public service capabilities for the E-commerce platforms is too low, it will also cause E-commerce platforms and collective organizations to choose noncooperation. The original supervision cost of the E-commerce platforms $\left(C_{p o}\right)$, operating costs of the collective organizations $\left(C_{c o}\right)$, original income of the E-commerce platforms $\left(S_{p}\right)$, and original income of the collective organizations $\left(S_{c}\right)$ have no influence on the final evolutionary result of the social cogovernance system.

From the above results, it can be concluded that E-commerce platforms must reasonably create cooperation spaces, collective organizations must strengthen public service capacity building, and government departments should rationally establish punishment and reward mechanisms. These are effective ways to enhance the willingness of the two parties to cooperate and increase the benefits of cooperation.

Simultaneously, the results show that E-commerce platforms and the initial strategies of collective organizations have an impact on the system's strategic decisions. Formulation of a reasonable punishment and reward mechanism by the government is critical for guiding the two parties to carry out efficient cooperation. Consequently, through reasonable guidance, the enthusiasm of the E-commerce platforms and the collective organizations to cooperate can be improved.

The numerical analysis of the simulation results indicates that when third parties, such as collective organizations, participate in social cogovernance systems, orderly rules should be constructed. The social cogovernance system for E-commerce intellectual property protection does not share rights and responsibilities equally, nor does it allow the third parties in society to participate in supervision without rules or responsibilities. The collective organizations with insufficient public service capabilities are unsuitable for participating in social cogovernance systems. The government is still the system's supplier for social cogovernance. However, the government, the E-commerce platforms, and the collective organizations need to coordinate to complete the system's supply.

4.2. Conclusions. Based on the theoretical analysis and numerical simulation of intellectual property protection of E-commerce through social cogovernance system and collective organization, this study draws the following main conclusions. First, the E-commerce platforms open up an adequately large space for a collective organization. This encourages the collective organization to increase its enthusiasm for cooperation, strengthen public service capabilities, and improve the efficiency improvement coefficient of its public service capabilities. This, in turn, can promote the construction of the social cogovernance system. Second, the introduction of a punishment and reward mechanism can ensure the quality and stability of the cooperation system. However, an unreasonable reward and punishment mechanism will inhibit the enthusiasm for system cooperation. The government should increase the rewards for the system and simultaneously provide a sufficient deterrence. This would increase the enthusiasm for cooperation. Third, by enhancing the initial preference of the E-commerce platform and collective organization for cooperation strategies, it is possible to promote the construction of an E-commerce social cogovernance system for the protection of intellectual property effectively.

This study innovatively introduces the social cogovernance theory and evolutionary analysis model in the field of E-commerce intellectual property protection in China. It streamlines the model with the reality of Chinese society through the cooperative coefficient, public service capabilities, and efficiency improvement coefficient. It is an active attempt to apply social cogovernance theory in the field of E-commerce. At the same time, it also provides a new perspective for the protection of E-commerce intellectual property rights.

However, it is difficult to numerically calculate the cooperation coefficients provided by E-commerce platforms and public service capabilities of collective organizations in practical applications. The main limitation of the study is that it is mainly a theoretical analysis. Future studies could provide more in-depth exploration in this field and find practical application scenarios to explore the rationality of constructing this social cogovernance system.

\section{Data Availability}

No data were used to support this study.

\section{Conflicts of Interest}

The authors declare that there are no conflicts of interest regarding the publication of this paper.

\section{References}

[1] J. Chen, S.-f. Huang, and Q.-r. Xu, "Firm innovation systems: perspectives of researches on state-owned key enterprises," Frontiers of Engineering Management, vol. 2, no. 1, pp. 64-70, 2015. 
[2] J. Chen, X. Yin, and J. Li, "Firm innovation system: paths for enhancing corporate indigenous innovation capability," Frontiers of Engineering Management, vol. 7, no. 3, pp. 404412, 2020.

[3] C. Pietrobelli and F. Puppato, "Technology foresight and industrial strategy," Technological Forecasting and Social Change, vol. 110, pp. 117-125, 2016.

[4] P. M. Romer, "Increasing returns and long-run growth," Journal of Political Economy, vol. 94, no. 5, pp. 1002-1037, 1986.

[5] L. Zhang and S. Huang, "New technology foresight method based on intelligent knowledge management," Frontiers of Engineering Management, vol. 7, no. 2, pp. 238-247, 2020.

[6] K. Mudrytska, "Specificity of proof in cases of infringement of intellectual property rights on sites on the internet," Science (Washington D C), vol. 5, no. 5, pp. 103-110, 2020.

[7] Y. Zhang, H.-H. Wei, D. Zhao, Y. Han, and J. Chen, "Understanding innovation diffusion and adoption strategies in megaproject networks through a fuzzy system dynamic model," Frontiers of Engineering Management, vol. 8, no. 1, pp. 32-47, 2021.

[8] Intellectual property, "Opinions on Strengthening the Protection of Intellectual Property Rights," 2021, http://www.gov. cn/zhengce/2019-11/24/content_5455070.htm.

[9] L. Illia, M. Bonaiuto, E. Pugliese, and J. van Rekom, "Managing membership threats through collective efficacy," Journal of Business Research, vol. 64, no. 6, pp. 631-639, 2011.

[10] J. C. Turner, M. A. Hogg, P. J. Oakes, S. D. Reicher, and M. S. Wetherell, Rediscovering the Social Group: A Self-Categorization Theory, Basil Blackwell, Hoboken, NJ, USA, 1987.

[11] S. B. Soderstrom and K. L. Heinze, "From paradoxical thinking to practicing sustainable business: the role of a business collective organization in supporting entrepreneurs," Organization \& Environment, vol. 34, no. 1, pp. 74-98, 2021.

[12] AhnHyojil, "Current situation of welfare services of collective management organizations and improvement suggestions," Copyright Quarterly, vol. 31, no. 4, pp. 101-136, 2018.

[13] D. Lopez-Berzosa and A. Gawer, "Innovation policy within private collectives: evidence on 3GPP's regulation mechanisms to facilitate collective innovation," Technovation, vol. 34, no. 12, pp. 734-745, 2014.

[14] N. R. Branscombe, N. Ellemers, R. Spears, and B. Doosje, “The Context and Content of Social Identity Threat," in N. Ellemers, R. Spears, and B. Doosje, Social Identity: Context, Commitment, Content, pp. 35-55, Blackwell, Oxford, UK, 1999.

[15] J. Liu, Q. Yin, and W. Chen, "The game analysis on the behavior of rural collective economic organization in the collective construction land transfer: based on the theory of hawk-dove game," Journal of Sichuan Agricultural University, vol. 33, no. 4, pp. 458-463, 2015.

[16] J. N. Rosenau, E.-O. Czempiel, and S. Smith, Governance without Government: Order and Change in World Politics, Cambridge University Press, Cambridge, UK, 1992.

[17] I. Ayres and J. Braithwaite, Responsive Regulation: Transcending the Deregulation Debate, Oxford University Press, New York, USA, 1992.

[18] C. Coglianese and D. Lazer, "Management-based regulation: prescribing private management to achieve public goals," Law e Society Review, vol. 37, no. 4, pp. 691-730, 2003.

[19] N. Gunningham and J. Rees, "Industry self-regulation: an institutional perspective," Law \& Policy, vol. 19, no. 4, pp. 363-414, 1997.
[20] S. Yang, J. Zhuang, A. Wang, and Y. Zhang, "Evolutionary game analysis of Chinese food quality considering effort levels," Complexity, vol. 2019, Article ID 6242745, 2019.

[21] Y. Zhu, M. Chu, X. Wen, and Y. Wang, "Food safety risk communication between the food regulator and consumer in China: an evolutionary game perspective," Complexity, vol. 2021, Article ID 9933796, 17 pages, 2021.

[22] L. Wu, P. Liu, Y. Lv, X. Chen, and F.-S. Tsai, "Social cogovernance for food safety risks," Sustainability, vol. 10, no. 11, p. 4246, 2018.

[23] X. Wang, "Governance logic and basic systems of the new "food safety Law of the people's Republic of China": a focus on social Co-governance," Journal of Resources and Ecology, vol. 9, no. 1, pp. 92-105, 2018.

[24] C. Shen and M. Wei, "An evolutionary game model for online food safety governance under two different circumstances," IEEE Access, vol. 8, Article ID 207691, 2020.

[25] Y. Kang, "Food safety governance in China: change and continuity," Food Control, vol. 106, Article ID 106752, 2019.

[26] M. Qiu and Z. Zhao, "Behavioral patterns of consumers participating in food safety and social co-governance: consumption choices and environmental improvement," E3S Web Conf.vol. 131, 2019.

[27] X. Wu, X. Huang, and Q. Liu, "Exploring a new social Cogovernance model of takeout food safety based on third-party supervision," IOP Conference Series: Earth and Environmental Science, vol. 512, Article ID 012072, 2020.

[28] K. Xie, Y. Liu, and X. Zhao, "The condition and strategy of media participating in food safety social Co-governance," Management Review, vol. 29, no. 5, pp. 192-204, 2017.

[29] X. Chen and L. Wu, "Psychological capital in food safety social Co-governance," Frontiers in Psychology, vol. 10, p. 1387, 2019.

[30] Z. Yang and Q. Li, "Research on the construction of social cogovernance system of ecological environment protection," IOP Conference Series: Earth and Environmental Science, vol. 632, no. 5, Article ID 052060, 2021.

[31] Z. Li, X. Yuan, J. Xi, and L. Yang, "The objects, agents, and tools of Chinese co-governance on air pollution: a review," Environmental Science and Pollution Research, vol. 28, no. 20, Article ID 24972, 2021.

[32] J. Hofmann, Internet Governance: A Regulative Idea in Flux, pp. 74-108, Icfai University Press, Hyderabad, India, 2007.

[33] W. Kleinwächter, "Internet Co-governance: towards a multilayer multiplayer mechanism of consultation, coordination and cooperation (M3C3)," E-Learning and Digital Media, vol. 3, no. 3, pp. 473-487, 2006.

[34] V. Babenko, Z. Kulczyk, I. Perevosova, O. Syniavska, and O. Davydova, "Factors of the Development of International E-Commerce under the Conditions of Globalization," SHS Web of Conferences, vol. 65, Article ID 04016, 2019.

[35] D. Christozov, S. Chukova, and P. Mateev, "On two types of warranties: warranty of malfunctioning and warranty of misinforming," Asia Pacific Journal of Operational Research, vol. 26, no. 03, pp. 399-420, 2009.

[36] M. A. Hossain, S. Rahman, T. A. Chowdhury, C. Chan, $\mathrm{X}$. Yang, and Q. Su, "How signaling mechanisms reduce "lemons" from online group buying (OGB) markets? A study of China," International Journal of Physical Distribution \& Logistics Management, vol. 48, no. 7, pp. 658-681, 2018.

[37] L. Shen, Y. Chen, R. Fan, and Y. Wang, "Government Supervision on Explosive Enterprises' Immoral Behaviors in E-Commerce Enterprises: An Evolutionary Game Analysis," Complexity, vol. 2021, Article ID 6664544, 11 pages, 2021. 
[38] D. Wen, D. Yan, X. Sun, and X. Chen, "Evolutionary Game Analysis of Online Shopping Quality Control: The Roles of Risk Attitude and Government Supervision," Complexity, vol. 2021, Article ID 5531076, 18 pages, 2021.

[39] L. Song, Q. Wang, and H. Shi, "Game analysis of behaviors among food safety governance subjects," E3S Web of Conferences, vol. 189, Article ID 02006, 2020.

[40] Z. Yang, Y. Shi, and Y. Li, "Analysis of intellectual property cooperation behavior and its simulation under two types of scenarios using evolutionary game theory," Computers \& Industrial Engineering, vol. 125, pp. 739-750, 2018.

[41] B. Li and D. Xu, "Evolutionary game analysis of financing model of intellectual property pledge: based on the perspective of supply chain finance," Journal of Beijing University of Posts and Telecommunications, vol. 20, no. 4, pp. 36-43, 2018.

[42] R. Xu, Y. Wang, W. Wang, and Y. Ding, "Evolutionary game analysis for third-party governance of environmental pollution," Journal of Ambient Intelligence and Humanized Computing, vol. 10, no. 8, pp. 3143-3154, 2019.

[43] D. Friedman, "Evolutionary games in economics," Econometrica, vol. 59, no. 3, pp. 637-666, 1991.

[44] B. Wu, J. Cheng, and Y. Qi, "Tripartite evolutionary game analysis for "Deceive acquaintances" behavior of e-commerce platforms in cooperative supervision," Physica A: Statistical Mechanics and Its Applications, vol. 550, Article ID 123892, 2020. 